\title{
Fifteen Years After - An Anthropological Field from a Diachronic Angle ${ }^{1}$
}

\begin{abstract}
By Maria Vivod*
The following contribution is the author's provision of a theoretical model of ethnoepidemiology as proposed by R. Massé (2008) on her research findings. Critical ethno-epidemiology here is used as an attempt to combine the strengths of direct participant observation, while taking into consideration the totality of all socioeconomic and cultural conditions and practices. The following paper argues that embracing the ethno-epidemiological method as a strategy of analysis is particularly valuable when changes on a given field are taken into consideration. Within a research project the author of the paper had the occasion to revisit the field of research done for her doctoral dissertation (1998-2004). The recent fieldwork (done during the first months of 2015), was conducted to verify the "state of the art" of ethnomedical practices in the same region in northern Serbia, as well as the present condition of the forms a of the popular (eventually: alternative) medical practices. Starting with the initial hypothesis, based on the prevalence of the so called "popular/traditional healers" in the region and on the forms of practices, the paper's aim is to compare the two sets of data. The goal is to present and to introduce a number of initial results and findings in a comparative manner with the intention to expose the observed changes which occurred in the meantime.
\end{abstract}

Keywords: Ethnoepidemiology, Health trends, Medical anthropology, New age medicine, Popular/traditional medicine, Serbia/Central Europe.

\section{Introduction}

The pivotal point of Massé's definition $(2001,2008)$ of critical ethnoepidemiology is the so called "social suffering" (la souffrance sociale).The study of social suffering is foremost an awareness of the causes of suffering, a concern about the life conditions of the population studied in the midst of poverty and political oppression. Massé's research refers mainly to the Martinique population which is a former slave-society still strongly impacted by colonization. The notion of "ethno-epidemiology" has acquired two different but intertwined meanings in the social sciences. On one hand, it refers to a developing cross-disciplinary health research methodology that combines direct participant observation and qualitative methods. The goal is to understand the social meanings and contexts as practiced in medical anthropology. The enterprise is the sampling, data collection, and mainly focusing on analytical strategies about risk factors and disease outcomes. Foremost, epidemiology must know how to deal with health economics.

\footnotetext{
${ }^{1}$ The research leading to these results has received funding from the European Research Council under the European Union's Seventh Framework Programme (FP7/2007-2013)/ERC grant agreement № 324214 .

${ }^{*}$ Researcher, University of Pécs, Hungary.
} 
Similarly, although the macro-micro-social lashing exists in all societies, coping with arrangements takes a specific staining in the Caribbean cultural context.

Critical ethno-epidemiology, unemployment, social isolation and poverty cannot be reduced to empirical variables which can be decontextualized or which are politically neutral (Massé 2001). They are living spaces that reflect the moral realities of unequal social relations. This phenomenological reading of the intermediate risk factors has to be accompanied with an analysis of the local interpretation of the causes of suffering. Interprimitivism is necessarily critical and the critical ethno-epidemiology finds its meaning in the relationship between the multiple layers of the lived reality of distress (idem). The elements exposed here are first attempt of the author to compare the two sets of fieldwork (1998-2004 and 2015) in a diachronic and qualitative manner.

The paper will first describe the two researches, the basic starting points and elements of the fieldwork, the used methodology the obtained results and the working theories which lead to conclusions. Then a brief comparison will follow which will describe and challenge an analysis of the divergences between the fieldworks. Next, an attempt will be made to reorganize the existing and the new results by the principles of critical ethno-epidemiology, as proposed by in R. Massé (2008) in his "Détresse Créole". This will be done in order, to analyze the present as well as the past data in a retrospective way according to the rules of the critical ethno-epidemiology as described by Massé. The goal of such scrutiny is the understanding of social meanings and contexts in ethno-medical practices with the intention to perceive eventual changes in these practices in a diachronic perspective, to notice ultimately new variations (new models of behavior) and to check the possible development of the popular nosology and health trends.

The fieldwork necessary to gather the material for the thesis was done in a period 1998-2004, in the province of Vojvodina, Northern Serbia. The research gathered various forms of practices. The thesis at the end concentrated on the practitioners themselves and their roles in the society. The practices I have encountered at the field at that time were still more or less "traditional" in the sense that they corresponded to the material I have found in the archived research and ethnographical articles from the 20th and the second half of the 19th century done on the same region and/or nearby.

Within the research project (funded from the European Research Council under the European Union's Seventh Framework Programme (FP7/20072013)/ERC grant agreement with the University of Pécs, Hungary) I had the occasion to revisit the field. The recent fieldwork (done during the first half of 2015), was conducted to verify the "state of the art" of ethnomedical practices in the same region, as well as the present condition of the forms a of the popular (eventually: alternative) medical practices.

The initial hypothesis was that there is going to be several divergences in the findings between those made fifteen years ago and those made this year as for instance in the prevalence of popular ethnomedical practitioners, as in the forms of these practices. 


\section{Research in 1998-2004}

The research collected various forms of practices, and the thesis at the end concentrated on the practitioners themselves and their roles in the society. The practices I have encountered at the field at that time were still more or less "traditional" in the sense that they corresponded to the material I have found in the archived research and ethnographical articles from the 20th and the second half of the 19th century. I have used the archived material done in the region, but also the material from the neighboring regions. Vojvodina is a home of more than twenty diverse ethno-linguistic-religious groups, from which some are autochthonous but almost all are originated from the neighboring regions (or in some cases now, countries). I have visited and revisited - and in some cases, spent prolonged periods of time - between 15 to 20 healers. I have located the healers I have chosen to study trough personal contacts. My choice was made on the following basis: every healer was recommended - either talked about, mentioned in a casual conversation by a person, who was at one time a patient, or an acquaintance of someone who was healed or treated in successful manner. In this manner I had the opportunity in advance to get familiar with the technique used by some particular healer and had a first-hand or second-hand experience from the treated person. This "recommendation" also facilitated my first contact with the healers: the "milieu" of traditional healers was - and still remains - a closed "scene". This circumstance is a result of interpersonal relationships based on trust and there is also the fact that most of the healing-treating exertions are often a parallel sources of income, unrecognized by the governmental institutions, which in a worst case label them as forms of "grey economies". At the time of the "first wave" of my fieldwork - mainly 2000 and 2001 - locating and contacting individuals practicing forms of traditional or alternative healing methods who usually lived in the rural parts of the region, was more or less difficult. Information circulated from mouth-to-ear - therefore a "recommendation" from a treated/healed individual was an almost natural way to get in touch with the healers. Some did not even have had a phone line and internet was at its beginning. I often dropped in people's houses in cases when I did not have had any concrete information (no phone, no address, just the name of the village). Usually during my visits, although unexpected, I was greeted kindly after the customary mistrust. I was refused only once for an interview. Fortunately for me, the person in question - an old man ( 84 years old at that time), a traditional chiropractor, distrustful of journalists - changed his mind; he welcomed me later on several occasions.

My standard field-methodology consisted in one-on-one interviews, free conversations on targeted topics. I usually returned for several times back and I filmed what I could - when I could. In those days, in my student-days, my access to camera and photo was limited. I did not have had any founding for my research, so I did the best I could with the limited means. I borrowed cameras and photos in order to make images that I later digitalized. 
At that time I analyzed the collected data as forms of local resistance to biomedical hegemony and also as a coping strategy toward a general lack in economic means and resources.

My stance at the time was similar to the mainstream-explanation of local scientists at that time (Làzàr 1996). The relatively increasing number of popular healers practicing some kind of a therapy claimed to be "traditional" was linked with mainly two factors: one if was the socio-economic crisis which "hit" hard the Yugoslav society in those years. There were shortages of all kind (a trade embargo was imposed starting from 1992) and this influenced more or less directly the access to healthcare. Also the socialist establishment crushed, introducing the country into a transitional state. This impacted directly the complete healthcare system. The second "big" factor was the re-birth of the so called "traditional values", a product of a growing nationalism, and a form of structural nostalgia (Herzfeld 1997). The "traditional values", embodied in church and religion and the "forgotten ancient" ways of therapy seemed to respond exactly to the needs of the population which (un)successfully tried to cope with the fall of the socialism, the successive civil wars and economic breakdowns ${ }^{1}$. The popular medicine which has been considered until that moment as "para" (often illegal) medicine has benefited of the "liberty of expression' and re-flourished. The popular healers started to leave behind the "traditional" and stereotypes of village milieus. This situation produced persons who successfully unified the traditional/popular know-how, modern techniques of publicity and information, and the instinct to respond on "special demands" of the potential customer or patient. The basis of the definition of illnesses and corresponding treatments were nevertheless still to be found in popular beliefs and cosmologies such as the creatures from the netherworld (curses, spells, fairies, demons, witches, werewolves, etc.). More or less unaware - looking back now - I have concentrated myself partially to the description of the status quo provided by the eastern European ethnographical currents that studied in some form either the popular healers or the spell-healers (bajalice in Serbian), incantations, the illness-bringing creatures - the fairies, demons, witches (i.e., Radenković, Pócs, Astahova, Bošković-Stulli, and many others). This movement had and still has a lot of representatives in Serbian, Croatian, Hungarian and several other schools of ethnography, and it is a part of a greater movement in Europe: studies in oral tradition and literature and popular beliefs (such as Ginzburg 1983, Lecouteux 1996, Murray 1972).

\section{Research in 2015}

My expectancies about the findings of the same field 15 years after my fist visit were more about the quantity of the popular healers in the region than about the variety of practices I estimated to encounter. I expected less so called "popular healers", believing that the relatively stable socio-political situation in the country lead the local population toward biomedicine. The cycles of the

\footnotetext{
${ }^{1}$ Yugoslavia went through a period of hyper-inflation between 1992 and 1995.
} 
armed conflicts of the Yugoslav wars had ended 15 years ago. The economic shortcomings that the population had experienced during those years when I first did research in the region were still present though. In many interviews I was told it was -worse than back then. Nevertheless I anticipated that the reform of the Serbian healthcare system made during the 2000s enabled the rural population to an easier access to healthcare.

In the first half of 2015 I have (re)visited $15^{1}$ popular, "traditional" practitioners and healers. I have introduced a "new category" in my methodology which was unknown to me in 1998-2004: the "unsuccessful" visits. I was led to it because of the increasing amount of popular healers who refused either to talk with me about what they are doing or to be interviewed or taped (audio/video/photograph). Some even refused to speak with me at all. The ratio of these encounters was 1:2, meaning that on every "successful" visit I had, at least, one unsuccessful ${ }^{2}$. This was a clear and visible change comparing to the period from a decade ago: the distrustfulness and the need of "privacy" of healers increased.

Due to the obligation to tape the interviews it was far easier for me to analyze the material comparing to the fieldwork 1998-2004 when I filled up entire notebooks with my writing (which I have now difficulties to decipher). There was just one occasion when the interviewed person (a new-age/reiki healer) insisted "dictating" what should or should not be recorded by me. It was also far easier to take photos and to film than in 1998-2004 ${ }^{3}$. The mandatory ethical codex that my colleagues and I use to get consent of the interviewed individuals - that previously I imagined as a great obstacle in convincing people to speak with me - has proved to be actually useful. It gave an "official air" to the interviews; it helped me explaining the whole research to them and the main goals of my research. In two-three occasions, a blanco-copy was demanded from me - which I obliged. Some people actually liked that they participated in a scientific research.

In summary, nevertheless, people were more distrustful now than in the past; not toward taping/filming (as was in 1998-2004), but toward me as a person, as a potential representative of "the public", of the "state". In one occasion a contact explained that the healer is afraid from potential taxes, of the governmental intermediaries such as tax-inspectors, community aldermen and journalists whose publication could draw an unnecessary attention. Some practitioners refused a conversation with me, for a simple fear of journalists ${ }^{4}$. Most of them reacted in a same way when they found out that I am not a potential "patient" but a scientist, doing research. In two occasions even the preliminary conversation "went wrong": the healer refused to permit me to introduce myself or the research. There were also different reasons for which I

\footnotetext{
${ }^{1}$ It is end of April 2015 and I am still going sporadically to fieldwork.

${ }^{2}$ At present 8 unsuccessful.

${ }^{3}$ It occurred to me that the camera at that time was far bigger and was taken by many for a professional, TV camera... .

${ }^{4}$ Unethical behavior of journalists are rather at daily order in Serbia.
} 
could not communicate with those I have studied in the past: several individuals ceased their activities (some due to their demise).

Was there any increase in the number of popular healers after a decade? Due to the nature of my methodology based on quantitative data collection it is difficult to assess. Almost every village has some form of "alternative healer": either "traditional", in which the practice is related to magical behavior, or popular chiropractic and ethnopharmacology. My personal evaluation is that since a decade ways of alternative medicine, either "traditional" or the "natural" (naturopathy) have become wide-spread and omnipresent even (or particularly) in remote villages. Official, biomedical practices seem just not to be enough.

The practices I have encountered at the field at that time were still more or less "traditional" in the sense that they corresponded to the material I have found in the archived research and ethnographical articles. New "waves" are now present even in small, geographically remote villages, as for instance new age healers (quantum-physics, reiki), forms of distant popular/traditional healing systems, such as acupuncture and acupressure, Asian massage and phytotherapy. There is a palpable increased awareness of foreign popular traditional medical systems that are or could be incorporated in the so called "traditional" healing methods, or serve as an authority. A rather interesting example of a woman which I followed during my research in 1998-2004 illustrates this adjustment well. She treated her patients in the past according to her words at the time with a "traditional method" - consisting of pulling the patient's hair in order to "open" his sinuses. Since, she enriched her vocabulary and she describes now her practice as form of acupressure. Her vocabulary completely changed and she speaks now about "appointments", "patients" and "treatments" and "points of pressure".

Some of the traditional/popular healers have Facebook pages and Youtube profiles; this practice helps any future patient (or researcher) to locate and choose a practitioner for his/her needs. Their names and contacts appear on diverse internet-forums by the successfully treated former patients. For instance, I have successfully located a woman who heals sinuses with a plantbeverage on a forum of moto-bikers.

However, the "traditional" healers I had the chance to encounter a decade ago who use magical-oral-traditional - fear (lead) melting technics (Vivod 2008), divination combined with traditional healing methods - proved more difficult to find. The question is this change is due to the transformation in health trends - increased number of people ask therapy against stress than "fright" (fràsz hung.) which was "the" illness treated with lead-melting (idem). Or the explanatory models have shifted? Treatments with prayers (Christian, Muslim) are relatively recent: interestingly a new religious group (dervish), due to the forced migration of a religious group from Kosovo, has made some changes in that sense. What is distinguishable is that treatments requiring a "material" method - the use of medicinal plants, massages, and form of "action" - are more present. 


\section{One Who Seeks - Pursues}

Years after supporting my PhD I got familiar with the ethnoepidemiological explanatory model which I sometimes felt suitable as a potential approach to (re)interpret my fieldwork data. Agar (1996) uses the term to refer to emic in the popular systems of disease understanding and response. Trostle (2005) introduces the term "cultural epidemiology" that an illness has in a given culture and the way it contributes to health trends made by culture.

For my work, the most appealing definition of ethnoepidemiology was given by Raymond Massé, a Canadian medical anthropologist. Massé has worked on the topic of the psychic despair at the islands of Martinique. According to him the s.c. "creole despair" is directly linked to the postcolonial social context of the islands. Starting from this premise, Massé elaborated the model of critical ethnoepidemiology. The despair as a way of social suffering has existential dimensions - interpersonal and intersubjective as well as collectives (Massé 2008: 19) and it expresses forms of embodiment of the human misery (Massé 1995 quoting Kleinman 1980: 14-16). Massé proposes beside a definition of critical ethnoepidemiology which does not establish any barrier between the social and the mental suffering actual criteria (idem).

In another volume, more geographically and socially similar to my own fieldwork, Làzàr and Luse (2007) analyze the human suffering as a social category per se. The book came right in time as an interpretation of events which shaped the 90s and are still constructing social realities across Europe and the world by filling the voids in understanding the human condition in general. The collection of case-studies addresses the relationship between suffering and the fall of the soviet-style state-socialism in which the term of a "post-communist" society is more broadly employed: in a form of "state imposed policies rather than socialism as political system" (Làzàr and Luse 2007: xi). As responses to the all-present suffering in the human condition alternative religious and medical practices, world views are still being constructed and (re)shaped. Although Làzàr and Luse do not use actually the term "critical ethnoepidemiology" as Massé advocates, their edited volume, as well as the publications which will follow afterwards (Hresanova and Szénassy 2011) point to what Massé proposed as a suitable definition, one with can work with (Massé 2008: 23-26): an interface between epidemiology and anthropology dedicated to the culturally situated analysis of nature, social distribution, causes and modalities of diverse expression of physical, mental and social sufferings (Massé 2008: 23). Massé also stipulates that ethnoepidemiology ambitions the mission to harness the potentialities of a third way between culture and politics, between popular knowledge and power (Massé 2008: 25).

Realizing that many of the former soviet (or communist, socialist) countries have traversed what I had the occasion to observe at the end of the 90 s and the beginning of the 2000s, I have embraced the idea of this theoretical model. 
Analyzing the findings from 2015 what becomes obvious in a diachronic perspective is that most of the available alternative, popular treatments and practices have to do with the alleviation of mental, psychological suffering. The number of alternative, traditional/popular practices did not decreased; although this conclusion is based on a personal assessment. Comparing to my hypothesis at that time that the economical shortages and the revival of (ethnic)identity-related practices ("traditional" medicine as a way going back to the roots) and that in that sense these practices flourished once the socialist era ended, I somehow expected (hopped?) that these practices would diminish. One possible explanation why this did not occur is that economical shortages are a "never-ending story" in Serbia. The economical "crisis" in Serbia seems to be a permanent condition and the impoverishment of the population in a free fall. So the need for closer, more available forms of medical practices is required as during wartime in the 90s. The condition in which the population turns toward these popular practitioners is more or less unchanged. These conditions are the fear of stigmatization, the suffering to which biomedicine doesn't know how to answer, the needs which are not related to the bodily pain, the remoteness of rural areas, situations when other treatmentpossibilities are exhausted, the circumstance that these treatments are uninvasive and so forth.

The diagnostic categories and the practices linked to the traditional/popular healing practices remain in the frame of sociocultural categories. Interestingly, only the vocabulary "evolved" in some cases in a very interesting manner: new concepts have become present, such as "stress", "incapacity to adapt" and have become categories per se. As new health trends increasingly influence the popular perceptions of "health" and "illness" so the (relatively) new and à priori foreign popular treatments are replacing those referred as "traditional". After accomplishing the fieldwork in this diachronic perspective I find Massé's critical ethnoepidemiology as more than suitable explanatory, theoretical model to the findings. It seems that this time-distance was necessary to have a suitable perspective to do so.

\section{Conclusion (Is There Ever One?)}

Massé's framework of critical ethno-epidemiology, although based on a post-colonial, post-slavery society, seemed foremost applicable in the case of Vojvodina because of the notion of social suffering. At the time when I did research during the "first wave" of fieldwork (1998-2004) the population of the region was slowly coming out of more than a decade of armed conflicts. And although the region was not "under war" - except for NATO bombardments in the spring of 1999 - the population - even the representatives of ethnic minorities - were drafted in the regular army and some as irregular (paramilitary) units and sent to battle on the territories of the former federation. The trade embargo (1992-1995), the downfall of the local currency (inflation) and many other socio-economic circumstances (such as the rise of crime, the 
brain-drain) had caused a lot of suffering in the lives of the local people. Although the period of socialism - under the era of Tito since the WWII - was characterized by an economic and social stability and was free of armed conflicts, one has to keep in mind that the average inhabitant of 70 years of the region of Vojvodina changed his or her citizenship between four or five times during his/her lifetime ${ }^{1}$. Vojvodina was and still is a very demographically and politically unstable region and this circumstance directly impacts the daily life of its population and moreover the conditions of wellbeing and health of individuals. For this reason I found the critical ethno-epidemiological model more than suitable in the analysis of the collected data. The roots of social suffering were deep, in some cases they reached back even for a couple of generations. This social-economic context was particularly pertinent in the comparison between the data of 1998-2004 and 2015. This diachronic condition enabled me as a researcher who mainly uses ethnographical methodology and qualitative analysis, to contextualize what I suspected back in 1998-2004. This diachronic perspective has shed light on several elements between the two sets of data: first, that experienced emotional and mental suffering is a pivotal point of the conditions and practices that I encountered 15 years ago and since then; suffering represents a challenge to the so called modern medical practices in Serbia. It seems that the popular, traditional practitioners, who practice a non-invasive, often a verbal-communicative treatment, offer a more suitable and personal approach in the management of conditions linked to ailments which are not of physical nature. Secondly, the distrust toward biomedical practitioners seems to be present in the same manner as it was 15 years ago. Going to a medical doctor represent a costly endeavor, especially for the rural population and distrust toward the pecuniary motivation of the representatives of modern medicine is even more present. One goes to a doctor only if it's really necessary and often as a last resource. Thirdly, the changes in the sociodemography of Vojvodina have become more visible in a lapse of more than a decade. A new ethnic and religious group has made Vojvodina its home ${ }^{2}$ and it is of a particular interest to observe how the newcomers got integrated and how they interact with other communities and ethnic minorities of the region. The diachronic study of these conditions made the critical ethno-epidemiological explanatory model very suitable in for the analysis of my research data.

The present fieldwork is still not completed while I finish this paper and probably the analysis of the data will necessitate a half year or even more. However the diachronic perspective seems to be of a great value and it is a privilege to re-visit a field after a more than a decade. This even more so in those cases, when the practitioner still is around and practices. Slight changes

\footnotetext{
${ }^{1}$ After the end of WWI (1918) the region which was a part of Austro-Hungarian Empire, it was attached to the Kingdom of Serbs, Croats and Slovenes, that became Kingdom of Yugoslavia (1923). After WWII (1945) Yugoslavia becomes a socialist federation (1945-1991). From 1992 the remaining parts of the federation (Vojvodina, Kosovo, Serbia and Montenegro) become Federal Republic of Yugoslavia until 2003. Than the country is known under State Union of Serbia of Montenegro until 2006. Since 2006 it's Republic of Serbia.

${ }^{2}$ The dervish community who fled Kosovo after 1999.
} 
in vocabulary, changes in the therapy and in the therapeutic "offer" - in cases of multiple techniques available by one healer - are remarkable ways to observe and to notice small changes that indicate and possibly give answer to the questions about the alterations at the macro-level.

\section{References}

Agar M (1996) Recasting the "Ethno" in "Epidemiology". Medical Anthropology 16(4): 391-403.

Herzfeld M (1997) Cultural Intimacy: Social Poetics in the Nation-State. New York: Routledge.

Hrešanová E, Szénássy E (2011) (Re)producing medical anthropology in central and eastern Europe. Cargo, Journal for Cultural and Social Anthropology 1(2). Prague: Czech Association of Social Anthropology.

Kleinman A (1980) Patients and Healers in the Context of Culture. Berkeley: University of California Press.

Lazar Ž (1996) Praznoverje i društvene promene (Superstition and social change). Gledišta XXXVII(3-4).

Lázár I, Luse A (2007) Cosmologies of Suffering Post-Communist Transformation, Sacral Communication, and Healing. Cambridge Scholars Publishing.

Massé R (2008) Détresse Créole. Ethnoépidémiologie de la détresse psychique à la Martinique (Creole Distress. Ethnoepidemiology of psychological distress in Martinique). Presses de l'Université de Laval.

Massé R (2001) Pour une ethno-épidémiologie critique de la détresse psychologique à la Martinique (For a critical ethno-epidemiology of psychological distress in Martinique). Sciences Sociales et Santé 19(1): 45-54.

Trostle J (2005) Epidemiology and Culture. Cambridge, UK: Cambridge University Press.

Vivod M (2008) Die Beschwörerin (Bajalica) Biljana aus Budisava, Wojwodina. Rekonstruktionsversuche einer ethnischen Identität im postsozialistischen Nachkriegsserbien (The Summoner (Bajalica) Biljana from Budisava, Vojvodina. An attempt to reconstruct an ethnic identity in the post-socialist post-war Serbia). Curare 30(2-3): 153-162. 